\title{
Climate change/variability implications on hydroelectricity generation in the Zambezi River Basin
}

\author{
Francis Davison Yamba • Hartley Walimwipi • \\ Suman Jain • Peter Zhou • Boaventura Cuamba • \\ Cornelius Mzezewa
}

Received: 13 January 2011 / Accepted: 13 January 2011 /

Published online: 23 June 2011

(C) The Author(s) 2011. This article is published with open access at Springerlink.com

\begin{abstract}
The study has analysed the effects of various factors on hydroelectric power generation potential to include climate change/variability, water demand, and installation of proposed hydroelectric power schemes in the Zambezi River Basin. An assessment of historical (1970-2000) power potential in relation to climate change/variability at existing hydro electric power schemes(Cahora Bassa, Kariba, Kafue Gorge and Itezhi-Tezhi) in the Zambezi River Basin was conducted. The correlation of hydroelectric power potential with climate change/variability aimed at observing the link and extent of influence of the latter on the former was investigated. In order to predict the future outlook of hydro electric power potential, General Circulation Models (GCM) were used to generate projected precipitation. The monthly simulated precipitation was extracted from the GCM for every sub basin and used to compute future precipitation. Further, future water demand in the sub basins of the Zambezi River Basin were estimated based on the respective population growth rate in each sub basin. Subsequently, water balance model, with projected precipitation and water demand input was used to determine projected run-offs of sub basins of the Zambezi River Basin. .Based on the projected run-offs of sub basins, reservoir
\end{abstract}

F. D. Yamba $(\bowtie) \cdot$ H. Walimwipi

CEEEZ-Centre for Energy, Environment and Engineering Zambia, Private Bag E 721, 176 Parirenyatwa Road, Suite B, Lusaka, Zambia

e-mail: ceeez@coppernet.zm

S. Jain

Department of Mathematics and Statistics, University of Zambia, P.O. Box 32379, Lusaka, Zambia

e-mail: sjain@unza.zm

P. Zhou

Energy, Environment, Computing and Geophysical Applications(EECG), Gaborone, Botswana e-mail:pzhou@global.bw

B. Cuamba

Department of Physics, Eduardo Mondlane University, Maputo, Mozambique e-mail: cuamba@nambu.uem.mz

C. Mzezewa

EnerConsult Pvt Ltd, 21a Wilson Drive, P.O. Amby Greendale, Harare, Zimbabwe

e-mail: ctmzezewa@zol.co.zw 
storage capacities at existing hydro electric power schemes were estimated. The baseline assessment revealed a strong relationship between hydroelectric power potential and climate change/variability. The study also revealed that the main climate and other risks associated with current and future hydro electric power generation include projected dry years, floods and increasing water demand. The results indicate that the hydroelectric power potential has a tendency towards gradual reduction in its potential in all existing and proposed hydroelectric power schemes owing to climate change and increasing water demand.

Keywords Climate change $\cdot$ Variability $\cdot$ Vulnerability $\cdot$ Adaptation $\cdot$ Hydroelectric $\cdot$ Power generation $\cdot$ Climate risk

\section{Introduction}

Although a great deal of research has been undertaken in global climate change world wide, very few studies have focused on specific regions. Studies are now emerging, which place emphasis on continental regions. For example, a recent study (Engelbrecht 2009) investigated the effects of increased greenhouse gas (GHG) emissions on the Southern African region's weather systems with emphasis on the influence of rainfall and temperature on water resources and agriculture. Further, studies (Arnel 2004) have investigated the implications of climate change on run-off in major regions of Africa. Although hydroelectricity contributes moderately to the energy supply of Southern Africa, few studies have examined the impacts of climate change on hydroelectricity supply in the region (Warren et al. 2006).

The study reported in this article was supported by Eskom Holdings Limited, South Africa under its Global and Regional Climate Change Impact Research portfolio. It assesses climate change/variability implications on hydroelectricity generation at the existing and proposed future hydro power stations in the Zambezi River Basin. In the recent past, a study (Harrison and Whittingtone 2002) has been undertaken focusing on the impact of climate change on the proposed Batoka gorge hydroelectric scheme in the Zambezi River Basin.

\section{Study background}

It is evident from recent drought occurrences in the Southern Africa Development Community(SADC) region (ECZ 2001) that there was a deficiency of water during the drought period 1991, which consequently affected hydropower generation and resulted in load shedding in most affected countries.It is also clear that there is enough historical evidence of the persistent occurrences of droughts. According to Intergovernmental Panel on Climate Change (IPCC) Third Assessment Report (AR3, 2001), water resources are a key area of vulnerability in Africa, affecting water supply for household use, agriculture and industry including hydroelectric power generation. The report states that Africa is the continent with the lowest conversion of precipitation to run off, averaging only $15 \%$ per annum.

The report concludes that most of Africa has invested significantly in hydro-electric power facilities. Reservoir storage in these facilities shows marked sensitivity to variations in run off and periods of droughts. This reservoir storage and the major dams in the region 
have reached critical levels threatening industrial activities. Model results of some reservoirs and lakes indicate that global warming will increase the frequency of such low levels of storage as a result of drought conditions (IPCC 2001).

In view of recent historical data on persistently occurring droughts in the region, and the implications for hydroelectric generation, the study aimed at assessing the potential impacts of climate change on run-off and consequently hydroelectric generation in the Zambezi River. The effects of climate change on river flows are uncertain, but any significant changes would have implications for hydroelectric generation. Climate change could affect the water level and seasonality in rivers which could affect the amount of electricity produced annually by hydro electric means and the timing of power production (ECZ 2001).

The Zambezi River Basin is the fourth-largest river basin of Africa, after the Congo/ Zaire, Nile and Niger Basins(FAO 2004). Its total area represents about $4.5 \%$ of the area of the continent and spreads over eight countries namely; Malawi, Mozambique, Zimbabwe, Zambia, Angola, Botswana, Namibia, and Tanzania as shown in Fig. 1. The Zambezi River flows eastwards for about 3,000 km from its sources in Kalene Hills, Northwestern Zambia to the Indian Ocean, and consist of 13 main river basins namely, Barotse, Cuando/Chobe, Kabompo, Kafue, Kariba, Lwanginga, Luangwa, Lungwe Bungo, Mupata, Shire/Lake Malawi, Tete, Upper Zambezi and the Zambezi Delta.

This study was undertaken by a multi disciplinary research team, to assess the potential impacts of climate change/variability on run-off, reservoir storage capacities and hydropower potential for both baseline (1970-2000) and projected (2010-2070) periods, and suggest corresponding adaptation/mitigation measures.

\section{Methodology}

The potential of the Zambezi River Basin was assessed for its capacity to supply both existing and projected hydropower requirements against projected climate change and variability. This required a definition of the Zambezi River Basin with respect to boundaries of main and sub basins, sub basin characteristics, and identification of major existing/ planned hydro electric power schemes and their respective characteristics. Sub basins characteristic included; surface area and number of meteorological stations, water demand and number of gauging stations while hydroelectric power schemes characteristics included reservoir storage capacities, head, surface area and power potential. Once definition was accomplished, modelling and network formulation of the Zambezi River Basin was conducted based on the water balance model (Pitman's model) or Water Resource Simulation Model (WRSM2000)(WRSM 2000), which is software used to simulate hydrological systems. WRSM2000 is of a modular construction, with four different types of modules(run-off, channel reach, reservoir and irrigation) linked by means of routes. The run-off module is the heart of WRSM2000.

Prior to utilisation of the WRSM 2000, calibration was undertaken for the purpose of adjusting the ground flow parameters based on baseline (1970-2000) historical data. Baseline historical data included, evapo-transpiration, reservoir storage capacities, surface area, rainfall, river flows, and water demand. In addition, pan factors were taken into account as input. This enabled the user to adopt pan-factor figures, provided suitable "crop factors" were available for natural vegetation. The growth of afforestation and impervious areas was represented by reading in values for up to ten different years. Ground flow parameters were built into the program and were adjusted accordingly during calibration. 
Upon calibration, the water balance model was used to generate projected river flows and reservoir storage capacities based on projected rainfall data (generated from GCM models) and water demand(generated using algorithms). This was followed by an assessment of the impacts of the projected run-off on storage capacity and hydroelectric power potential.

\subsection{Definition of Zambezi river basin-}

The Zambezi Basin is located between a latitude of $8^{\circ}$ to $20^{\circ}$ South, and a longitude of between $16.5^{\circ}$ to $36^{\circ}$ East draining an area of about 1.385 million $\mathrm{km}^{2}$. It covers about $25 \%$ of the total area of its 8 riparian states (Fig. 1) comprising of Angola, Botswana, Malawi, Mozambique, Namibia, Tanzania, Zambia and Zimbabwe. The Zambezi River rises on the central African plateau in the Kalene hills in North Western Zambia at 1,585 m above sea level, flowing to the delta in Mozambique before draining into the Indian Ocean (FAO 2004).

The existing hydropower facilities considered under the study included Kafue Gorge, Itezhi-Tezhi, Lake Kariba between Zambia and Zimbabwe and Cahora Bassa in Mozambique. Further, proposed hydroelectric scheme sites were studied, and these included the Batoka and Mupata Gorges on the Zambia/Zimbabwe Zambezi river boundaries (Fig. 2) and Mepanda Uncua in Mozambique.

\subsection{Modelling and networking formulation}

In order to model the Zambezi River Basin, various hydrological features and other features relevant to the study in the Zambezi River Basin were identified. These features include main reservoirs, main tributaries, irrigated areas, surface water abstraction etc. Modelling was performed for the baseline scenario, depicting existing features, as well as the projected scenario depicting both existing and proposed hydropower schemes.

The modelling process involved (a) identification and location of hydrological features (main reservoirs, main tributaries), (b) determination of sub basin boundaries and their

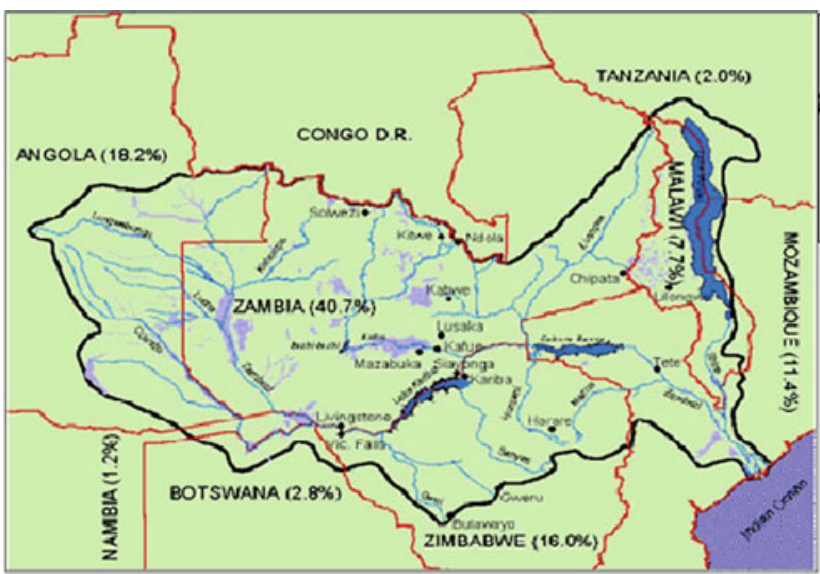

Source: Zambezi River Authority

Fig. 1 Zambezi basin river systems

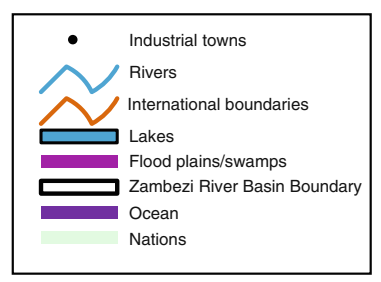




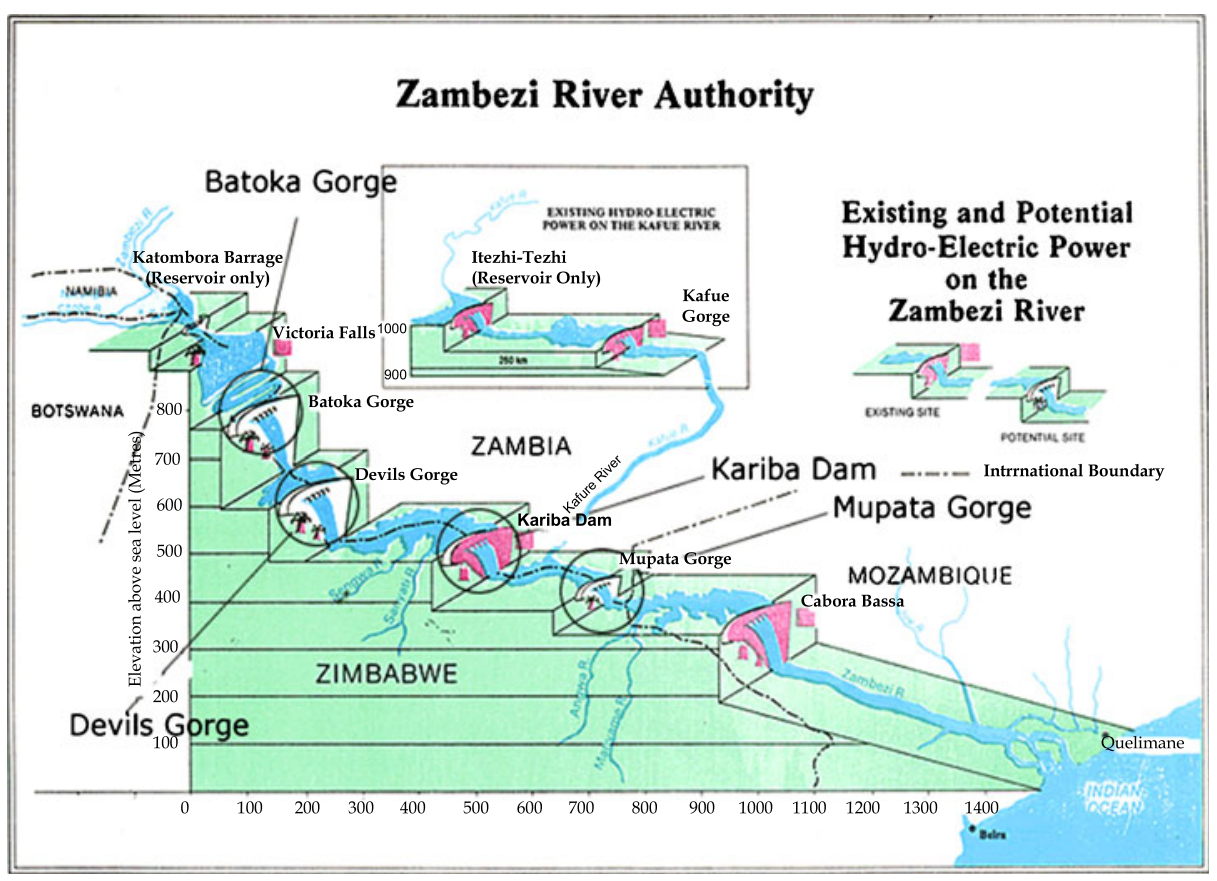

Fig. 2 Schematic layout of the actual proposed and existing hydroelectric power schemes

respective catchment areas, (c) identification and location of other relevant features to water balance modelling (i.e. irrigated areas, water abstraction for towns and industries) and, (d) identification and location of gauging stations on tributaries of the Zambezi River Basin. This was followed by drawing of the network diagram containing the above mentioned features. Ultimately, a network was created in the WRSM 2000 software based on the network diagram consisting of routes and run-off, channel reach, and irrigation modules (Appendix 1).

\subsection{Assessment of water demand}

In this study, proportion of water use for irrigation, domestic, industrial and commercial activities was estimated and served as input into the water balance model for the purpose of its calibration in the baseline scenario.

\subsection{Precipitation GCM scenarios}

Precipitation scenarios were generated using the following general circulation models:

- CCCMA-second version of the Canadian Global Coupled model run by the Canadian Centre for Climate Modeling and Analysis (CCCMA) on the resolution of longitude $3.75^{\circ}$ and latitude $3.68^{\circ}$

- CSIRO Mk2-run by the Commonwealth Scientific Industrial Research Organisation based in Australia on resolution of longitude $5.61^{\circ}$ and latitudes $3.14^{\circ}(625 \mathrm{~km}$ by $350 \mathrm{~km}$ ) 
- HADCM3 run by the Hadley Center in UK on resolution of longitude $3.75^{\circ}$ and latitude $2.5^{\circ}$.

The precipitation scenarios were generated using the daily precipitation $(\mathrm{mm} / \mathrm{day})$ data from the above three models under GHG emissions IPCC scenario SRES A2. The A2 storyline assumes a world in which the emphasis is on local solution to economic, social, and environmental sustainability. It is a heterogeneous world with less rapid, and more diverse technological development but with a strong emphasis on community initiative and social innovation to find local, rather than global solutions (IPCC 2001).

Thirty (30) years monthly precipitation time series for the periods 2010 to 2040 and 2040 to 2070 for every sub basin was generated using Eq. 1. The precipitation data for each sub basin was extracted by obtaining baseline time series $(\mathrm{O})$ of monthly total precipitation for each sub basin in the period 1970 to 2000 from Meteorological Departments in the region (Malawi, Mozambique, Zambia and Zimbabwe). This was then followed by extracting HADCM3, CCCMA, CSIRO precipitation data for the control period 19702000 (C) and results from the former and the latter were compared closely. Based on this correlation, future periods (F1) 2010-2040 and (F2) 2040 to 2070 for grid boxes with sizes relative to the sub basins were carried out. The respective extracted gridded data for control (C) and future (F) from HADCM3, CCCMA, CSIRO were averaged to obtain the overall control $(\mathrm{C})$ and future $(\mathrm{F})$ values. The overall (averaged) control $(\mathrm{C})$ and future $(\mathrm{F})$ data were then used to determine the future monthly precipitation (Eq. 1) and provided input into the water balance model.

$$
P_{p}=O+\left(\frac{F-C}{C}\right)
$$

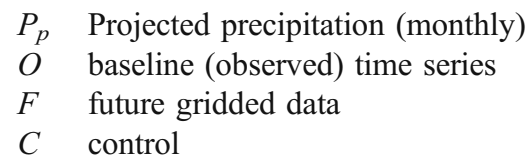

From the GCMs grid data projections, future monthly rainfall values were generated for the period 2010-2070 together with their respective anomalies. The generated mean monthly rainfall from the GCMs for the control period were observed to be oscillating around the measured historical monthly mean. In some cases, the departure of the generated monthly mean from historical monthly mean was considerably high for each of the GCM used. Figure 3 representing one of the sub basins shows a comparison of observed and modelled monthly means for the period 1970-2000 for the three GCM models considered.

Because of the anomalies pointed out above, confidence can not be based on the results from one single GCM. The trend and magnitude of the average of the monthly mean precipitation for CCCMA, CSIRO and HADCM3 for the control period was found to generally characterize the observed monthly mean precipitation as shown in Fig. 4.

\subsection{Use of water balance model}

Water balance modelling depends on hydro-meteorological data and surface water run-off conditions in catchment areas. The Water Resource Simulation Model 2000 (WRSM 2000) 
Fig. 3 Observed and model monthly means for the period 1970-2000 for Kabompo

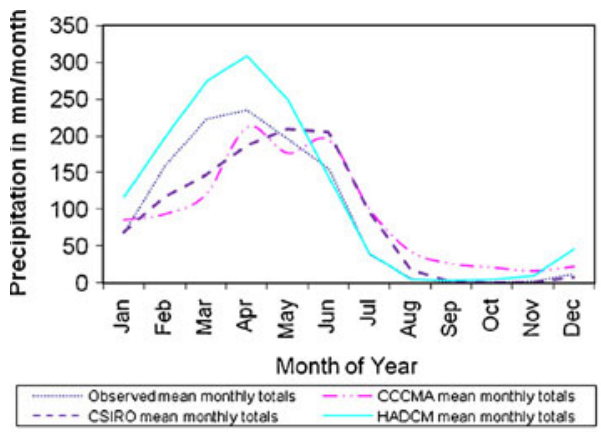

was used to determine surface and sub-surface run-off (Q) after accounting for evapotranspiration losses, soil moisture and groundwater flows based on Eq. 2.

$$
P=Q+E \pm S \pm G
$$

\section{$P \quad$ precipitation or rainfall \\ $Q \quad$ surface and subsurface run-off \\ $E$ evapo-transpiration losses \\ $S$ change in soil moisture \\ $G$ change in groundwater, (Pitman, 2001)}

Prior to carrying out projected run-off simulations, calibration of the WRSM was conducted. During calibration, the model parameters were adjusted by trial and error process till the model indicators closely reproduced the observed stream flow at various gauging stations on the tributaries of the Zambezi River. The model parameters included: power of soil moisture/subsurface flow equation(POW), soil moisture state when subsurface flow $=0(\mathrm{SL})$, soil moisture capacity in $\mathrm{mm}(\mathrm{ST})$, subsurface flow at soil moisture capacity (FT), maximum groundwater flow in $\mathrm{mm} /$ month $(\mathrm{GW})$, minimum catchment absorption in $\mathrm{mm} / \mathrm{month}$ (ZMIN), maximum catchment absorption in $\mathrm{mm} / \mathrm{month}$ (ZMAX), interception storage in $\mathrm{mm}$ (PI), lag of flow (excluding groundwater (TL), lag of groundwater flow in months (GL) and Coefficient in evaporation/soil moisture equation (R).

The model indicators were; mean annual runoff (MAR), standard deviation of annual flows (S), coefficient of variability (S/Mar), coefficient. of skewness, autocorrelation coefficient of annual flows, mean of logs of annual flows, standard deviation of logs of

Fig. 4 Station and model averaged monthly means for 1970 2000 for Kabompo

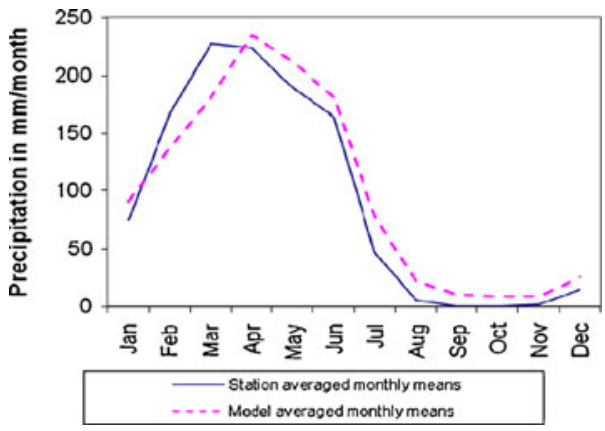


Fig. 5 Simulated and observed stream flow at Watopa gauging station on Kabompo sub basin

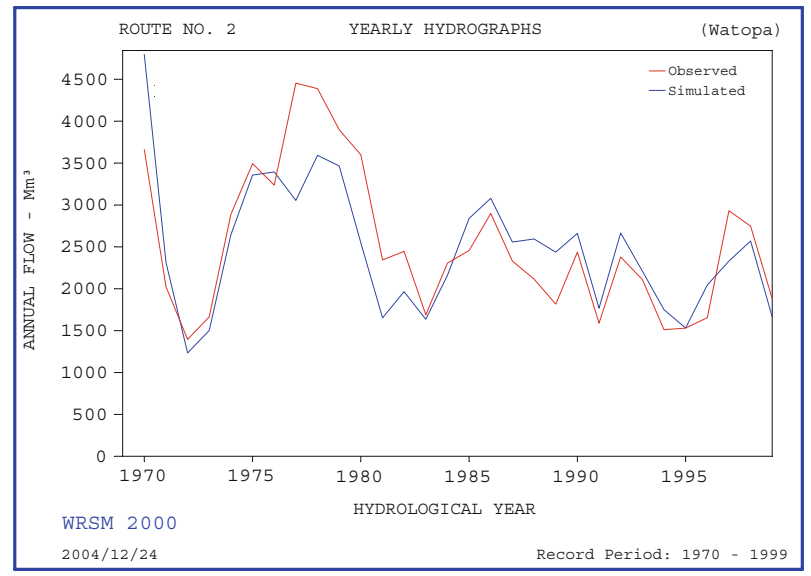

annual flows and seasonal index variability,. To close up difference among the simulated and observed indicators, calibration parameters were adjusted until a satisfactory Equivalent was reached. Shown on Fig. 5 is the model calibration for one of the gauging stations (Watopa on Kabompo sub basin).

With this confidence level, the water balance model was then used to assess projected run-off on all the sub basins and their effects on reservoir storage capacities and hydroelectric potential for existing and planned hydroelectric schemes. Given on Fig. 6 is projected runoff for one of the sub basins.

\subsection{Use of water demand}

In this study, water demand forecasting for each sub basin was done based on baseline water demand and growth rate. In the SADC region, water demand is projected to rise by at least $3 \%$ annually until the year 2020, a rate nearly equal to the region's population growth rate (UNEP 2006). This was used as a basis to forecast water demand for each sub basin of the Zambezi Basin.

\subsection{Effects of installation of proposed power stations on run-off}

The effects of installation of proposed new power stations on run-off are determined using the water balance model equation developed earlier. Except in this case, consideration is

Fig. 6 Projected run-off trends for Kabompo sub basin

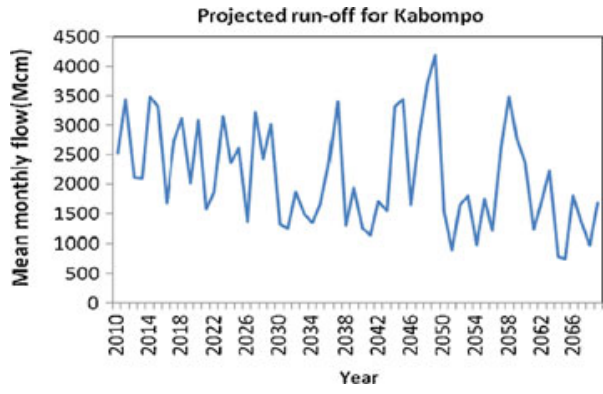


taken of increased losses due to the same effects especially evapo-transpiration losses due to increase of new surface areas of the new installed infrastructure.

3.8 Calculation of hydroelectric power potential for Itezhi-Tezhi, Lake Kariba, and Cabora Bassa

The projected theoretical power potential was assumed as the gross hydropower potential. It was estimated from a knowledge of the effective head of the each of the reservoir dams , annual run-off entering the reservoirs, density of the water and the gravitational force as given in the Eq. 3.

$$
P_{\text {Gross }}=\frac{\rho_{\text {WATER }}{ }^{*} g^{*} H_{\text {GROSS }} * Q}{10^{6}}
$$

$$
\begin{array}{ll}
P_{\text {Gross }} & \text { gross power }(\mathrm{MW}) \\
\rho_{\text {WATER }} & \text { density of water }\left(\mathrm{kg} / \mathrm{m}^{3}\right) \\
G & \text { acceleration due to gravity }\left(\mathrm{m}^{2} / \mathrm{s}\right) \\
H_{\text {GROSS }} & \text { gross head }(\mathrm{m}) \\
Q & \text { annual run-off into the reservoir }\left(\mathrm{m}^{3} / \mathrm{s}\right)
\end{array}
$$

\section{Results}

To determine the gross theoretical projected hydroelectric power potential on the major hydroelectric schemes, namely the Itezhi-Tezhi, Lake Kariba and Cabora Bassa required the effects of run-off and water demand to be taken into account. Run-off was determined using GCM models which generated monthly precipitation under the projected scenario from2010 to 2070. Figures 7 and 8 show existing (Itezhi-Tezhi, Lake Kariba, Cahora Bassa) and proposed (Mepanda Uncua) gross theoretical hydroelectric power potential.

It is evident from results obtained that hydroelectric power potential has a tendency towards a gradual reduction for all the hydroelectric power schemes, both existing and
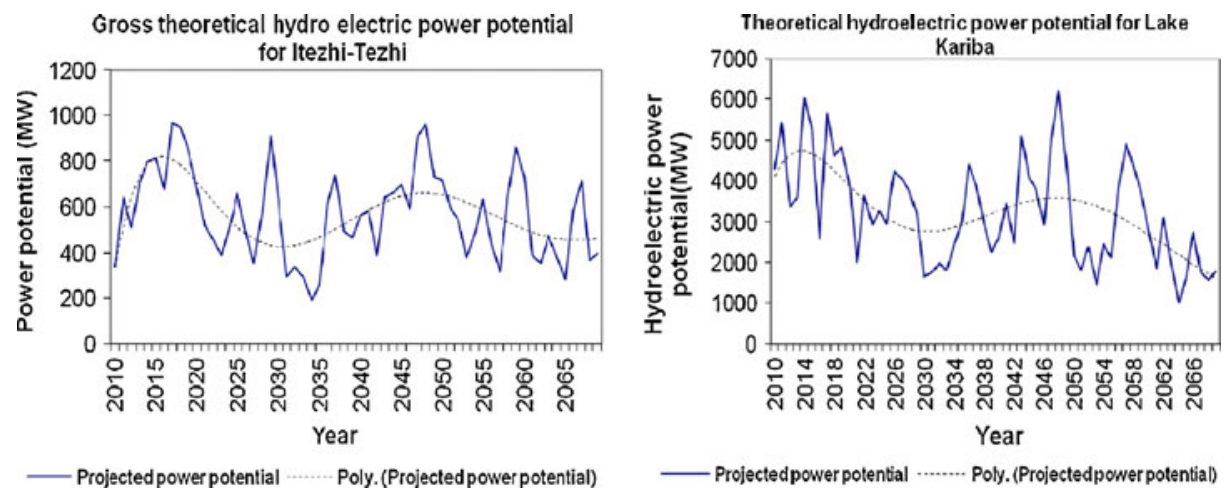

Fig. 7 Gross theoretical hydroelectric power potential for Itezhi-Tezhi and Lake Kariba 

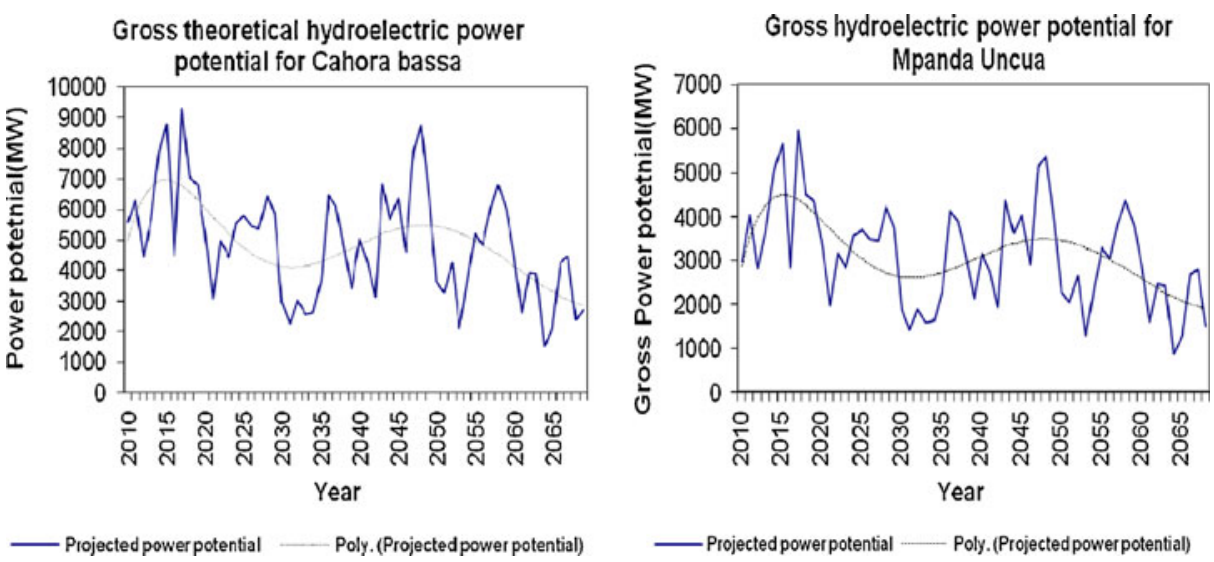

Fig. 8 Gross theoretical hydroelectric power potential for existing Cahora Bassa and proposed Mphanda Nkwa schemes

proposed. Generally, it is projected that there will be extreme occurrences of either higher rainfall or droughts in all the hydroelectric schemes considered.

In the case of Itezhi-Tezhi, between 2010 and 2017 there will be a tendency for increased hydropower potential followed by a deep reduction up to 2026. Between 2026 and 2050, there will be a reduced recovery compared to the 2010 to 2018 period. Thereafter, a gradual reduction is expected. As regards Kariba, the overall tendencies are that of reduced hydroelectric power potential over the projected period, with a recovery between 2010 to 2018 , followed by a prolonged reduction until 2030. From 2030, there will be a reduced recovery until 2048, after which hydroelectric power potential will continue to reduce.

The predicted trend in power potential for Cahora Bassa is similar to that of Kariba as run-off from Kariba goes into Cabora Bassa. As such, it would appear that the Kafue sub basin run-off has not much influence, probably due to the relatively smaller catchment size with reference to the size of total catchment area comprising of Cahora Bassa together with the Kafue catchment. The predicted trend for hydropower potential variations for Mepanda Uncua is similar to that for Cabora Bassa, except that it is smaller in magnitude. According to the WRSM simulations, there were no failures recorded on the reservoir storage capacity of Mepanda Uncua as a result of the installation of the Mupata, Batoka, and Devils Gorge schemes.

\section{Conclusions}

The study has revealed that the main climate and other risks associated with current and future hydro electric power generation include projected dry years which will likely result in droughts. Consequently, the resulting droughts are likely to reduce run-off and hence reservoir storage capacity resulting in reduced power generating capacity. Projected wet years which are likely to result in floods pose a threat to damage to hydroelectric infrastructure. On the other hand, projected increase in water demand is likely to reduce run-off resulting in reduced power potential. 
To mitigate against such risks, the following are being suggested; inter-basin water transfers, regional integration of electricity infrastructure from hydro to include biomass sources, use of alternative energy sources and effective water management. During dry episodes, inter-basin transfers can help mitigate the water shortfall needed for power generation in sub basins that contain hydropower installations. These basin transfers will allow some schemes to mainly run and operate as run-of-river schemes. This will allow storage at Kariba, Itezhi-Tezhi and Cahora Bassa for use in the dry seasons. Transfers will be more economical in cases where it is not possible to generate electricity on site. From the foregoing analysis, it is very clear that Zambian River systems have the biggest potential for hydroelectric power generation and most transfer schemes appear feasible (Tumbare et al. 2000).

Regional integration of hydroelectricity electricity infrastructure to include natural gas and biomass sources has also greatest potential in providing electricity to the SAPP region. With the existence of SAPP, this development is possible. For hydro sources, it is important that regional projects such as Kafue Lower and Itezhi-Tezhi in Zambia, rehabilitation of existing Inga in the Congo DR, and development of natural gas power stations in Mozambique, Namibia and South Africa are considered as part of the adaptation strategy. In the long term, the grand Inga scheme should be considered as a vision for the future, since it lies in a different basin (Congo River basin) which is termed to be rich in water resources.

Apart from considering hydro based power stations on a regional basis, which can be regarded as renewable, other alternative energy resources include the following; pumped storage electricity generation, which involves use of pumped storage schemes to generate electricity on a continuous basis at selected hydropower stations, and biomass in the form of agriculture and forest wastes. Biomass is a large resource in Southern Africa, which can be converted into fuels for electricity generation either as isolated schemes or feeding into the SAPP grid. Other measures include effective integrated water management system in view of the expected increase in water demand in the Zambezi River Basin and energy efficiency and early warning systems.

Acknowledgements The authors would like to sincerely thank ESKOM for providing advice and financial support which has enabled successful completion of this study under the leadership of Centre for Energy, Environment and Engineering Zambia (CEEEZ). During the period of the study we received not only financial support but also very useful critique from ESKOM's technical experts that helped us to guide, shape and focus the direction of the study and enabled us to avoid many mistakes. We apologise for not being able to mention the names of all them. Special thanks go to Maria Couto, Clive Turner, Neil Snow, Siven Naidoo and Sanjiv Kalicharan.

CEEEZ wishes to recognise the invaluable contribution of the team members in this study. The team comprised of the following: Prof F.D Yamba, Dr P. Zhou, Dr B. Cuamba, Mr C, Mzezewa, Mr C .Chikusa, Mr L. Nyahuma, Mrs S. Jain, Mr H. Walimwipi, and Mr G. Phiri.

We also wish to extend our gratitude to organisations and institutions that contributed to the success of this study. We are indebted to Zesco, Zambezi River Authority (ZRA), Meteorological and Water Affairs Departments (i.e in Zambia, Malawi, Mozambique and Zimbabwe), for providing us with useful data utilised in this study.

Open Access This article is distributed under the terms of the Creative Commons Attribution Noncommercial License which permits any noncommercial use, distribution, and reproduction in any medium, provided the original author(s) and source are credited. 


\section{APPENDIX 1}

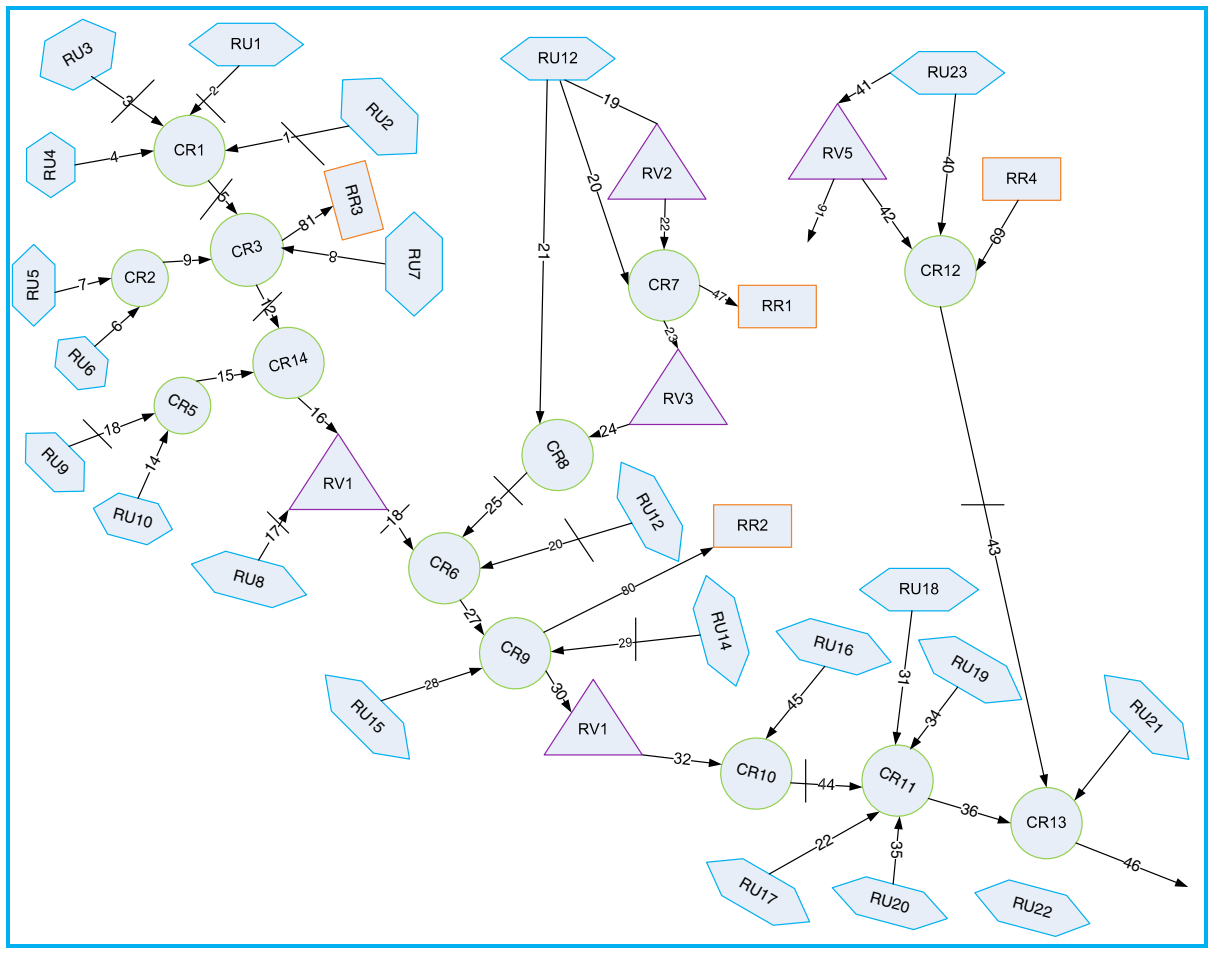

Fig. 9 Baseline network diagram

\section{References}

Arnel NW (2004) Climate change and global water resources, SRES emissions and social economic scenarios. Glob Environ Change 14:31-51

Environmental Council of Zambia (ECZ) (2001) State of the Environment in Zambia

Engelbrecht F (2009) Climate Simulation of Southern African Region. Published Morrison, L, in Engineering News-Volume 29 Number 2 ISSN 02578646 January 23-29 2009

FAO Corporate Document Repository (2004) http:/www.fao.org/

Harrison G, Whittingtone P (2002) Susceptibility of the Batoka Gorge hydroelectric scheme to climate change. J Hydrol 264(1-4):230-241

IPCC (2001) IPCC Synthesis Third Assessment Report

UNEP (2006) Net. Water resources; WWW.UNEP.Net/Africa/freshwater, the Environment Network

Warren RN, Nicholls R, Levy P, Price J (2006) Understanding of regional impacts of climate change,

Research Report prepared for the Stern Review on Economics of climate change, Tyndal Centre for

Climate Change Research, Working Paper number 90, UEA, Norwich, p 221

Tumbare, et al. (2000) Management of river basins and dams: the Zambezi River Basin

WRSM (2000) Water resource simulation model operation manual 